
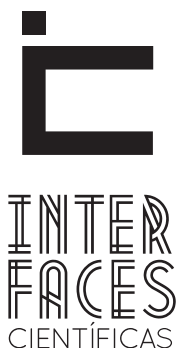

EDUCAÇÃO

\title{
DISCIPLINA NA ESCOLA: REFLEXÕES SOBRE A REALIDADE PORTUGUESA
}

Ana Isabel M. Silva ${ }^{1}$

\section{RESUMO}

Nos dias atuais qualquer pessoa ligada ao quotidiano, ou as práticas escolares, tem conhecimento sobre a "indisciplina". Os profissionais da área falam da existência de tal indisciplina, mas não apontam a sua extensão nem as razões exatas. Alguns pais se deparam de muito perto com esta tal indisciplina e o "aluno-problema”, que traz consigo certos distúrbios psicológicos e/ou pedagógicos, de natureza tanto cognitiva quanto comportamental. Ao longo do texto vamos abordar o desenvolvimento da criança e do adolescente, os comportamentos típicos desta fase e terminamos com uma reflexão sobre algumas razões da indisciplina e da agressividade nas escolas. Esperamos com esta reflexão dar o nosso contributo para a compreensão da indisciplina na Escola.

PALAVRAS-CHAVE:

Indisciplina. Disciplina. Escola.

\section{ABSTRACT}

In the current days any person connected to the everyday life, or the school practices, have knowledge about the "indiscipline". Professionals in this area speak of the existence of such indiscipline, but do not indicate its extension or the exact reasons. Some parents are facing very closely such indiscipline and the "student-problem", that brings with it certain psychological disorders and/or pedagogical in nature both cognitive and behavioral. Throughout the text we will address the development of child and adolescent, the typical behaviors of this phase and finished with a reflection on some reasons of indiscipline and aggressiveness in the schools. We hope with this reflection to give our contribution to the understanding of indiscipline in school.

\section{KEYWORDS}

Indiscipline. Discipline. School 


\section{RESUMEN}

Hoy en día cualquier persona relacionada con el cotidiano, o con las prácticas de la escuela, tlene conocimiento acerca de la "indisciplina”. Los profesionales del área hablan de la existencia de tal indisciplina, pero no señalan su alcance ni sus razones exactas. Algunos padres se enfrentan de muy cerca con la indisciplina y con el "alumno-problema” que trae con él ciertos trastornos psicológicos y / o pedagógicos, de naturaleza tanto cognitiva como de conducta. A lo largo del artículo abordamos el desarrollo del niño y de los adolescentes, las conductas típicas de estas fases y terminamos con una reflexión sobre algunas de las razones de la indisciplina y de la agresividad en las escuelas. Esperamos con esta reflexión dar nuestra contribución a la comprensión de la indisciplina en la escuela.

\section{PALABRAS CLAVE}

Indisciplina. Disciplina. Escuela.

\section{INTRODUÇ̄̃O}

Alguns pais se deparam de muito perto com esta tal indisciplina e o "aluno-problema", que traz consigo certos distúrbios psicológicos e/ou pedagógicos, de natureza tanto cognitiva quanto comportamental. Algumas considerações devem ser feitas a este respeito. A primeira é que o conceito de disciplina varia conforme a exigência de cada um. A segunda é o facto de que a indisciplina é geralmente referida como distúrbio, desvio, como se o natural fosse a disciplina.

Contudo a transgressão e a agressividade são inerentes ao ser humano e fundamentais para o desenvolvimento do indivíduo e da sociedade, princi- palmente quando nos referimos a períodos como pré-adolescência e adolescência.

Obviamente este facto não dá a estas crianças o direito de agredir e transgredir o que quiserem e quando quiserem, a imposição de limites é também factor determinante para o bom desenvolvimento das crianças e adolescentes.

0 que as crianças e os adolescentes ouvem acerca da comunidade escolar não os ajuda a formar uma boa ideia do que é a escola de seu papel e importância. Ou só ajuda a denegri-la ainda mais reforçando a ideia de que não se deve respeitar este espaço?

\section{DESENVOLVIMENTO NA INFÂNCIA}

A partir das décadas de cinquenta e sessenta, os estudos centrados no desenvolvimento infantil dão ênfase à influência do envolvimento parental e dos educadores na educação da criança, salientando que as experiências precoces interativas desempenham um papel fundamental no desenvolvimento e crescimento ulterior da criança (SILVA, 2011).
Em todo o mundo, as crianças crescem, segundo uma mesma sequência. Algumas parecem voar muito rapidamente em direção a certos «marcos» do desenvolvimento, enquanto outras são mais lentas. A maioria das características que fazem de cada indivíduo um ser único são resultantes da interação entre o «modelo» biológico já presente no 
óvulo fertilizado e as vivências da criança em crescimento (SYLVA; LUNT, 1994).

Nesta perspetiva Fonseca e Mendes (1977 apud SILVA, 2011) referem que a atividade da criança começa por ser elementar e caracterizada por um conjunto de gestos sincréticos sem qualquer significado ou objetivo, gestos que são à partida a expressão de uma modulação tónica de reação ao meio que a envolve.

Segundo Stommen (1986 apud SILVA, 2011) salienta que todos os aspetos do desenvolvimento de uma criança estão interrelacionados. Muitos comportamentos só aparecem quando as estruturas necessárias já se desenvolveram. 0 desenvolvimento psicológico pode influenciar o desenvolvimento físico assim como ser influenciado por aquele.

A mesma autora, refere que para que o crescimento global da criança se verifique, é necessário que se construam condições favoráveis para o seu desenvolvimento. Se não se envolver a criança em condições emocionais positivas, o seu sistema muscular tende a atrofiar-se e os sistemas circulatório, respiratório e endócrino podem apresentar insuficiências funcionais e fisiológicas, que se virão a refletir num desenvolvimento desarmónico e, por vezes, aberrante. Ainda segundo estes autores, a formação do psicológico passa pela formação do biológico, ou melhor, a formação do pensamento na criança assenta no ajustamento dos seus movimentos, não podemos esquecer que a formação de qualquer das condutas da criança exige, pois, a presença do adulto, sem ele, a criança não poderia integrar uma determinada experiência sócio histórica.

Muller (1977, p. 44), relata a experiência de Winterbottom no seu interrogatório às mães sobre as metas educacionais e as suas técnicas educacionais, concluindo que: "O resultado foi inequívoco: as mães dos alunos aplicados, durante os primeiros oito anos de vida, tinham recompensado com amor, reconhecimento e ternura cada execução independentemente de tarefas".
Orth (1971, p. 9) fala-nos da importância da afetividade para o desenvolvimento cognitivo partindo da observação de que crianças deficientes mentais (constatando o mesmo em muitas crianças normais e até intelectualmente superiores à média) não obtêm sucesso devido a bloqueios afetivos: “É incontestável o papel acelerador ou perturbador da afetividade nas operações da inteligência, [...] não existem mecanismos cognitivos sem elementos afetivos, [...] não existe estado afetivo sem elementos cognitivos".

Fica registrado, pois, que a afetividade é muito importante para um bom desenvolvimento intelectual, no entanto não nos podemos esquecer do desenvolvimento cognitivo e de como este se processa.

Vigotski (1995) inaugura uma nova abordagem do processo de desenvolvimento infantil, analisando-o pelo prisma das leis da lógica dialética. Em sua perspetiva, o desenvolvimento não constitui um processo puramente evolutivo, que se processaria pela via de mudanças lentas e graduais, mas caracteriza-se por ruturas e saltos qualitativos e mudanças essenciais nas próprias forças motrizes do processo.

Nesse sentido, o autor postula que o desenvolvimento caracteriza-se pela alternância de períodos estáveis e críticos. Nos períodos estáveis, o desenvolvimento se deve, principalmente, a mudanças “microscópicas” da personalidade da criança, que vão se acumulando e se manifestam mais tarde como uma repentina formação qualitativamente nova em uma idade. Assim, nos períodos de crise produz-se mudanças e ruturas bruscas e fundamentais na personalidade da criança em um tempo relativamente curto, produzindo uma nova qualidade de relação da criança com o meio circundante.

Vigotski (1995, p. 141) compreende o desenvolvimento infantil como:

[...] um processo dialético que se distingue por uma complicada eriodicidade, a desproporção no desen- 
volvimento das diversas funções, as metamorfoses ou transformações qualitativas de umas formas em outras, o entrelaçamento complexo de processos evolutivos e involutivos, o complexo cruzamento de fatores externos e internos, um complexo processo de superação de dificuldades e de adaptação

O que determina diretamente o desenvolvimento da psique de uma criança é a sua própria vida e o desenvolvimento dos processos reais desta vida. É preciso, assim, analisar o conteúdo da atividade da criança e como essa atividade é constituída nas condições concretas de vida. Só com este modo de estudo pode-se elucidar o papel, tanto das condições externas de sua vida, como das potencialidades que ela possui (LEONTIEV, 2001).

A análise de Leontiev (2001) sobre o papel da atividade no desenvolvimento intelectual, corroborada por Elkonin (1987), não se refere, contudo, à atividade da criança em geral, mas a determinados tipos de atividade que são mais importantes para o desenvolvimento em determinados estágios do desenvolvimento.

Trata-se do conceito de atividade principal. Para Leontiev (2001, p. 63), a atividade principal é aquela cujo desenvolvimento governa as mudanças mais importantes nos processos psíquicos e traços psicológicos da personalidade da criança em cada estágio de seu desenvolvimento: "devemos, por isso, falar da dependência do desenvolvimento psíquico em relação à atividade principal e não à atividade em geral”.

Cabe destacar que a atividade principal não é aquela que ocupa mais tempo na vida da criança durante um estágio de seu desenvolvimento, mas aquela: a) no interior da qual surgem e se diferenciam outros tipos de atividade; b) na qual os 6 processos psíquicos parti- culares tomam forma ou são reorganizados; c) da qual dependem, de forma mais íntima, as principais mudanças psicológicas na personalidade infantil (LEONTIEV, 2001).

A transição de um estágio do desenvolvimento a outro se dá, para esse autor, pela mudança do tipo principal de atividade:

surge uma contradição explícita entre o modo de vida da criança e suas potencialidades, as quais já superaram este modo de vida. De acordo com isso, sua atividade é reorganizada e ela passa, assim, a um novo estágio no desenvolvimento de sua vida psíquica. (LEONTIEV, 2001, p. 66).

Para Vigotski (1995), Davidov (1988) evidencia a aproximação entre o conceito de atividade principal adotado por Leontiev ao conceito de situação social de desenvolvimento, e proposto por ele em 1996. A situação social de desenvolvimento se refere à relação que se estabelece entre a criança e o meio que a rodeia, que é peculiar, específica, única e irrepetível em cada idade ou estágio do desenvolvimento. 0 mesmo autor refere que a situação social de desenvolvimento é o ponto de partida para todas as mudanças dinâmicas que se processarão no desenvolvimento, durante aquela determina idade e determina as formas e a trajetória que permitem à criança adquirir novas propriedades da personalidade.

Para Davidov (1988), a aproximação entre os dois conceitos fica evidente ao considerarmos que a situação social de desenvolvimento se refere, antes de tudo, à relação da criança com a realidade social, tendo em vista que essa relação se realiza precisamente por meio da atividade humana.

\section{DESENVOLVIMENTO NA ADOLESCÊNCIA}

A palavra adolescente significa em latim "crescer" e indica um período de mudanças. Após uma aborda- gem conceptual, emerge a noção da existência de um desenvolvimento biopsicossocial. Assim, adolescên- 
cia é caracterizada, essencialmente, por alterações sequenciais e interligadas, que vão desde o corpo, 0 pensamento, a vida social e o Eu (REYMOND, 1995).

O início da adolescência é por muitos discutido e não existe um consenso. Segundo Cordeiro (1997), este período vai desde os 10 anos aos 19 anos, para outros o início começa aos 11 anos e finaliza com a entrada no mercado de trabalho.

É uma fase da vida - etapa de desenvolvimento, merecedora de uma atenção especial, tal como nos referem autores como Louise Pepin (1979) e Daniel Sampaio (1998).

A adolescência é um espaço de transição entre a infância e a idade adulta, marcada por importantes alterações; nomeadamente biológicas, que resultam do despertar do metabolismo endócrino a que se associam modificações corporais, tais como: aceleração da velocidade de crescimento, mudanças das características sexuais, entre outras.

É considerado um período de crise/mudança, situando-se entre dois pólos importantes: Dependência (proteção) e Independência (autonomia), caracterizando-se por contradições, confusões, ambivalências, conflitos com os pais e com a função parental, e de procura de identidade e autonomia (CORREIA; ALVES, 1990).

Sobre esta temática, destacamos do estudo (SILVA, 2004, p. 41), alguns testemunhos de Pais e adolescentes:

"Agora tenho que a ouvir primeiro" (mãe, 48 anos, meio urbano);

"Diz que já não é criança, mas gosta de brincar" (pai, 43 anos, meio urbano);

"Poêm-me de castigo, mas não obedeço, ninguém vê." (adolescente, 12 anos, meio urbano).

O adolescente já não aceita a condição infantil, e encara o futuro, incitado pela escolarização. A esco- la solicita o sentido de responsabilidade, sendo necessário fazer opções. Estas opções, ultrapassam a informação e a capacidade de raciocínio, tendendo o adolescente a recusar os conselhos dos pais, ouvindo de boa vontade os dos pares, como confirma os testemunhos do nosso estudo:

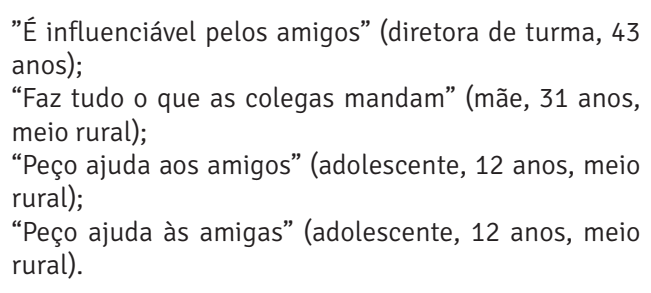

Como refere Almeida (1987), a evolução psicológica do adolescente ocorre paralelamente em quatro campos interligados: o emocional, o sexual, o intelectual e o social, e engloba basicamente as seguintes etapas:

1 - a interiorização das alterações físicas;

2 - o estabelecimento de um novo tipo de relações;

3 - o aparecimento de um comportamento social responsável;

4 - a evolução para uma personalidade em equilíbrio com os valores éticos da cultura vigente;

5 - a capacidade para planear e orientar as suas atividades futuras.

Existe uma tendência para generalizar esta fase como se todas fossem iguais. Tal não é o caso como nos refere Cordeiro (1997), pois existem tantas adolescências como adolescentes e a generalização pode conduzir a uma indesejada e perigosa estandardização, criando parâmetros pelos quais, segundo esta ótica, todos os adolescentes se deveriam reger. No entanto, existem características biopsicossociais que são comuns aos vários adolescentes, o que difere é 
o modo como se concretizam em cada adolescente, pois existem características específicas adquiridas na infância.

Fenwick e Smith (1995) salientam que durante a adolescência existem "marcos" emocionais e intelectuais pelos quais um ser humano tem de passar até atingir a idade adulta. Não é obrigatório todos passarem e exibirem estas características e comportamentos típicos, a seguir referenciados, mas segundo os mesmos autores existe um padrão geral de maturação que se poderá dividir em três estádios da adolescência: inicial, média e tardia.

Na adolescência inicial, que vai dos 11 aos 14 anos, os aspetos principais são as alterações hormonais. Isto resulta num maior cuidado e preocupação com a aparência do corpo em desenvolvimento e ao mesmo tempo uma inibição. Com as alterações hormonais surge, igualmente, um comportamento rebelde, provocador, agressivo e mau humor geral e os amigos começam a ter uma maior importância (FENWICK; SMITH, 1995).

O segundo estádio, adolescência média, vai dos 15 aos 16 anos. Segundo os mesmos autores, os marcos desta fase são essencialmente o do adolescente se tornar menos alocêntrico, o de desenvolver maior capacidade de cedência e aprender a pensar em si mesmo e a tomar as suas decisões. Em termos morais, começa a questionar conceitos e valores, criando os seus próprios valores. Com o decorrer das amizades o ponto da sexualidade desenvolve-se também. 0 adolescente aceita a sua sexualidade, cria relacionamentos sexuais envolvendo sentimentos que talvez nunca tenha enfrentado. Intelectualmente, começa a ter interesses mais amplos e uma maior curiosidade pelo mundo que o rodeia.

Por último, a adolescência tardia que decorre entre os 17 e 18 anos, onde ocorrem mudanças que são direcionadas para a independência e são, essencialmente, seis: torna-se idealista, envolve-se com a sociedade (no trabalho e nas relações fora da família), dedica-se a um curso para obter independência finan- ceira ou emocional, mostra-se mais apto para relacionamentos sexuais mais estáveis, sente-se adulto em pé de igualdade perante os pais e está quase pronto para se tornar um adulto independente e autoconfiante (FENWICK; SMITH, 1995).

As idades mencionadas são apenas uma referência e em qualquer dos estádios as raparigas tendem, geralmente, a serem mais precoces no processo de maturação que os rapazes.

O desenvolvimento da personalidade exige que a relação com o meio seja reestruturada, sendo a atitude da família muito importante.

O final da adolescência é difícil de delimitar, dependendo da estrutura da personalidade e dos aspetos socioculturais em que o adolescente se insere (CORREIA; ALVES, 1990), encontrando-se bem delimitada em algumas culturas e menos delimitada noutras.

Nas sociedades tradicionais, esta transição caracterizava-se por uma passagem abruta para a idade adulta, através dos ritos de iniciação ou de passagem, que podiam ser de curta ou longa duração, realizar-se de forma simples, alegre e festiva ou obedecer a um ritual complicado com cerimônias austeras, onde desde sacrifícios a atos aparentemente "bárbaros", tudo é aceito com grande solenidade e gravidade (SILVA, 2004)

Ao longo da história e com as grandes revoluções sociais, a adolescência tem sofrido novas influências, adquirindo novas perspetivas, sem contudo perder as suas características gerais. Assim, não se pode pensar que existe um só tipo de adolescentes iguais a si próprio no tempo e no espaço, mas que a adolescência constitui um tempo de passagem "em falso", um tempo em que tudo é definido pelo negativo: não se é criança, mas, também, não se é adulto (ALMEIDA, 1987).

Enquanto nas sociedades tradicionais os adolescentes não se afirmavam como um grupo independente e o rito era coordenado pela hierarquia social, 
nas sociedades modernas o rito é imposto pelos adolescentes, que tomam a iniciativa, contra a opinião da hierarquia social, surgindo uma nova perspetiva de valores morais e sociais, nomeadamente: o dinheiro, o que representa, o modo como é utilizado; a independência e os meios de transporte; ocupação de tempos livres e a música; a vida social, a habitação, o estudo e o trabalho; o casamento e a fecundidade; a mortalidade; a participação política, a religião. (SILVA, 2004, p. 43).

\section{COMPORTAMENTO}

As transformações físicas da adolescência, tal como nos refere Sprinthall \& Collins (1999) começam quando o hipotálamo estimula a glândula pituitária a segregar determinadas hormonas, estas por sua vez estimulam os ovários, os testículos e as glândulas adrenais a produzir outras hormonas.

Ainda, para os mesmos autores as alterações físicas, súbitas e repentinas, que os adolescentes experimentam, dão a este período do desenvolvimento um aspecto típico de autoconsciência, sensibilidade e preocupação sobre as mudanças do próprio corpo, e de comparações tormentosas entre si próprios e seus pares. As mudanças físicas nem sempre ocorrem de maneira sincronizada e, por isso, os adolescentes podem passar por estágios de inaptidão, tanto em termos de aparência como de mobilidade/ coordenação física. Estados de ansiedade desnecessários podem surgir se as adolescentes não forem informadas e preparadas para a menarca (o início dos períodos menstruais) e se os meninos não receberem informações e preparo adequado para o início das emissões nocturnas.

De acordo com Silva (2004), durante a adolescência é normal que os jovens tenham e demonstrem a necessidade de se separarem dos pais e estabelecerem as suas próprias identidades. Em alguns casos, as reacções podem ser mínimas da parte dos envolvidos. Em algumas famílias, porém, podem surgir conflitos significativos entre os atos e gestos de rebeldia dos adolescentes e as necessidades dos pais de manterem o con- trolo e de terem os seus filhos se comportarem como crianças obedientes. A mesma autora acrescenta:

\begin{abstract}
No desenvolvimento da adolescência, vai surgir uma libertação da tutela parental em troca de uma envolvente relação com os grupos pares, nas quais o jovem vai adquirir a sua vida social. É nesta instituição dos pares que o adolescente procura as suas referências sobre as normas e estatuto. (SILVA, 2004, p. 51)
\end{abstract}

Porém, cada vez mais o grupo de companheiros proporciona ao adolescente uma oportunidade de identificação, uma proteção (particularmente a nível da sua própria sexualidade) e uma exaltação (a força do grupo contraria a fraqueza do individuo). Na sociedade ocidental o modo preponderante de socialização é, tradicionalmente, no seio da família (FRASQUILHO, 1996).

Na verdade cada sociedade constrói as expectativas de comportamento dos adolescentes. Estas expectativas são condicionadas pelos valores erigidos pelas diferentes classes sociais dentro de cada sociedade (FLEMING, 1993).

No entanto, Gills (1991) refere que os jovens de hoje vivem o mundo diferente da forma como os mais velhos vivenciaram, mas ambos partilham heranças comuns. Contudo, existem diferentes gerações, pelas situações novas a que os jovens estão sujeitos, mas existem igualmente uma enorme continuidade dentro de cada classe, género ou grupo étnico. Cada geração redefine as suas tradições de forma a dar 
resposta às suas necessidades particulares (FLEMING, 1993).

Fleming (1993) sublinha a existência de uma disfunção entre a capacidade procriativa do jovem (maturidade biológica mais cedo atingida que no passado) e a sua capacidade socioeconómica (acesso à casa e ao emprego retardados), se tem vindo a acentuar, encorajando-se, por um lado a separação do jovem da família de origem e retardando-a, por outro, já que de um modo geral o jovem permanece hoje até tarde no seio da família.

Ouillon e Origlia (1974), referem que o papel do grupo na socialização do adolescente pode ser bom ou mau, dependendo dos casos. 0 que verificamos é que as relações sociais na adolescência se identificam com a procura de amizades. É na adolescência que a amizade se reveste de maior importância.

A influência dos colegas sobre os adolescentes é notória na nossa sociedade, bem como a sua rejeição pelos valores dos pais, em favor dos valores e comportamentos dos pares.

\section{RAZÕES DA INDISCIPLINA E DA AGRESSIVIDADE}

Como qualquer sistema, a Educação integra uma pluralidade de elementos interrelacionados: alunos, professores, curricula, escolas e a própria organização e administração educativa.

0 prolongamento da obrigatoriedade escolar em Portugal, as mudanças inerentes à reforma educativa não acompanhadas das reestruturações necessárias, o insucesso escolar, transportado muitas vezes para insucesso pessoal, as escolhas muito precoces na área vocacional, ao nível do desenvolvimento do adolescente, são fatores que têm implicações nos adolescentes e nos professores.
A luta dos jovens à condição adulta pode-se tornar angustiosa e repleta de incertezas diante da necessidade de cortar os laços de dependência infantil para entrarem num mundo futuro desconhecido (REYMOND, 1995).

É na escola que o indivíduo procura a sua identidade social, pois é aqui o ponto de encontro com a sociedade, adquirindo novas relações e capacidades. A escola torna-se, assim, não apenas uma instituição social com funções gerais de formação, mas também um meio de desenvolvimento do indivíduo.

A integração nos grupos pares vai oferecer um conforto no jovem, pois este encontra-se no meio de gente "igual”, com as mesmas transformações físicas e psicológicas.

Todo o processo de socialização é reconhecido como condicionante na estruturação e conclusivo do processo adolescente, por ter um enorme significado a nível funcional para a sua estabilização. Assim, o adolescente atinge a sua individualidade e integração social que será uma estrutura base na sua vida adulta (SILVA, 2004).

Os alunos e professores passam grande parte do tempo em que estão "acordados" na escola. Os professores interagem com os alunos, e os alunos com os professores; os alunos interagem uns com os outros e com materiais escolares.

À medida que professores e alunos interagem uns com os outros, desenvolve-se um grupo. Os professores referem que cada turma adquire uma "personalidade distinta”, por sua vez os alunos diz que a sua turma é "ótima” ou "não é assim tão boa” e relembram durante anos uma determinada turma ou a sala de convívio. 0 que os alunos lembram mais frequentemente não é aquilo que o professor ensinou, mas sim 
as dimensões sociopsicológicas da turma (ARENDS, 1997 apud SILVA, 2004).

Tal como na família, os adolescentes solicitam limites e regras para se sentirem contidos e reassegurados. Estes limites são por eles várias vezes testados, situa-se ao nível físico, ao nível psicológico e social. Os limites psicológicos e sociais são sistematicamente solicitados e por vezes rejeitados, pelos adultos e mesmo do grupo de iguais. Este teste de limites, resulta dessa necessidade de experimentação, com o objetivo de se reassegurarem da existência de um suporte externo, contentor dos seus movimentos (MEDEIROS, 2000).

Neste sentido, as estruturas e os processos que os professores escolhem para adaptar nas turmas influenciam a forma como estas se desenvolvem e as normas que elas estabelecem para a aprendizagem social e escolar.

Proporcionar liderança para fomentar ambientes de sala de aula produtivos será uma função crítica da liderança realizada pelos professores. Estes ambientes produtivos para Arends (1997), são caracterizados: um clima geral em que os alunos têm sentimentos positivos sobre si, os colegas e a turma, estrutura e processos em que as necessidades dos alunos são satisfeitas e um contexto em que os alunos adquirem as competências de grupo e interpessoais necessárias à realização das exigências escolares e grupais da turma.

Vários investigadores, nomeadamente Lippitt (1958), Shmuck (1963) citados por Arends (1997) mostraram que o comportamento do professor tem uma influência importante na vontade dos adolescentes, para cooperarem e aderirem às tarefas de aprendizagem. A partir destes estudos concluíram que os professores que são demasiado severos e autocráticos, podem obter muito trabalho dos seus alunos, enquanto estão fisicamente presentes, mas que esse envolvimento decairá assim que se ausentarem. En- quanto, que os professores laissez faire apresentam problemas para os alunos, porque os grupos ou turmas sem liderança têm dificuldade em persistir nas suas tarefas e em definir expectativas sobre a realização bem sucedida.

Sprinthall e Collins (1994) afirmam que as escolas secundárias têm negligenciado, na sua grande maioria qualquer abordagem do adolescente enquanto pessoa. É de tal forma importante a dimensão sócioafectiva na escola na adolescência que investigadores, nomeadamente Goodlad et al (1984, in Sprinthall \& Collins, 1999) chegaram à conclusão de que os estudantes concordam que as escolas secundárias devem estabelecer um grande equilíbrio entre quatro áreas de desenvolvimento: intelectual, social, pessoal e vocacional. No entanto, os adolescentes destacam como a melhor coisa que a escola thes oferece os colegas, seguindo-se os desportos.

A firmeza no caminho para a autonomia é muito importante no contexto escolar, tal como no contexto familiar, ambas se complementam, sem se anularem ou excluírem.

Sprinthall e Collins, (1999), salientam, ainda, que se durante a adolescência sofrêssemos uma modificação drástica dos padrões de comportamento, atitudes e valores, teríamos de passar por uma desaprendizagem dos modelos anteriores e por uma cuidadosa aquisição de novos modelos. Esta aprendizagem descontínua tornaria a adolescência muito mais difícil do que o normal para a maioria dos jovens.

Como assinala Medeiros (2000) a família com fiIhos adolescentes passa por uma das crises normativas do seu desenvolvimento. Os movimentos de mudança coevolutiva são necessários e notórios em todos os membros da família e no sistema na sua globalidade, pelo que o sistema passa por uma adaptação estrutural que permite a continuidade funcional e organizacional. 
Os pais dos adolescentes defrontam conflitos e por vezes dificuldades num processo de (re)afirmação da identidade semelhante ao dos filhos, embora de modo diferente. Sentem-se por vezes pressionados por uma carreira profissional frustrante ou demasiadamente absorvente. Poderão viver desiludidos com um casamento estéril, ou no qual já se apagou a chama. Sentem-se confusos, indecisos e culpabilizados face à geração precedente (dos próprios pais) que agora tenta reaproximar-se devido à necessidade de apoio e proteção. Toda esta pressão pode contribuir para as dificuldades de negociação junto do adolescente, apontadas muitas vezes como falta de diálogo, de paciência, de atenção, em suma, como uma certa negligência parental com entrega dos filhos a terceiros: escola, grupo de amigos, entre outros (MEDEIROS, 2000). Vão neste sentido alguns dos testemunhos dos adolescentes do estudo empírico (SILVA, 2004, p. 80):

“A mãe não ouve, sinto-me muito sozinha [...] 0 pai raramente está em casa" (adolescente, 12 anos, meio rural);

"Os meus pais não têm paciência para mim" (adolescente, 12 anos, meio urbano);

"A mãe não ouve" (adolescente, 12 anos, meio rural).

Baunrind (1965 apud SPRINTHALL; COLLINS, 1999) classificou os pais em: autoritários, permissivos e autorizados. Nas famílias "autoritárias", os pais são rígidos e controladores, sendo o ambiente emocional da família muitas vezes frio e distante.

As famílias "permissivas", pelo contrário, fazem poucas exigências aos filhos, enquanto as "autorizadas" têm características comuns com as anteriores, mas possuem limites e expectativas no que respeita ao comportamento dos filhos. 0 ambiente afetivo destas famílias é geralmente caloroso e de aceitação.

Neste sentido, estudos realizados em relação aos efeitos dos estilos educativos dos pais em diferentes culturas (dinamarquesa, estilo predominantemente democrático e a norte-americana, predominantemente autoritário) e subculturas, em função de diferen- ças étnicas e de classe social, mostram que, onde há maior discussão e partilha na tomada de decisões, é notório os filhos apresentarem um maior inconformismo, sentimento de independência e liberdade, maior autoestima e a predominância de um "locus" de controlo interno. Observaram, também, uma maior consonância entre as atitudes e comportamentos destes adolescentes e as atitudes parentais, na cultura dinamarquesa em classes média-alta e alta. Constataram que o estilo educativo permissivo resulta numa escalada de comportamentos, sendo os mesmos de rejeição parental e de carácter antisocial, que fogem totalmente ao controlo dos pais (SPRINTHALL; COLLINS, 1999).

Relativamente a esta temática destacamos alguns testemunhos de pais do estudo (SILVA, 2004, p. 82), no que respeita a estilos educativos:

"Quando é preciso eu mando" (mãe, 47 anos, meio rural).

“Eu mando e não se discute nada lá em casa, ela não sabe nada" (pai, 45 anos, meio rural).

"Incentivo o meu filho ao diálogo, faço-lhe perguntas e explico-lhe as coisas. Temos uma comunicação aberta" (mãe, 52 anos, meio urbano).

Os pais não se podem demitir da sua autoridade parental, têm que aprender a regulá-la e a conduzi-la a níveis de flexibilidade que facilitem a sua diminuição progressiva.

Digamos que o grau de autonomia concedido deverá oscilar, em função das situações e dos temas nelas envolvidos, entre um limiar máximo que impeça a colisão da autoridade parental com a dignidade do adolescente, com a sua necessidade de afirmação, autoestima e confiança pessoal crescentes, e um limiar mínimo de controlo que possibilite o suporte e segurança de que ele também necessita. (MEDEIROS, 2000, p. 63)

Uma investigação, conduzida por Smetana (1987, citado em Sprinthall e Collins (1999), na qual procurou determinar como é que os pais e adolescentes definem as respetivas áreas de poder e autoridade, considerou três domínios de comportamento: "con- 
venções", comportamentos julgados na base do acordo mútuo, outro referente a "atos morais", julgados na base do respeito por princípios universais, e outro considerado "pessoal”, julgado na base da discriminação individual. Considerou, ainda, uma área de comportamentos mistos de escolha pessoal e convencionais (o tipo de roupas que se usa, arrumação do quarto).

Este autor chegou às seguintes conclusões: pais e filhos estão de acordo quanto à legitimidade do exercício da autoridade parental, sobre temas convencionais e morais. Em relação aos domínios pessoal e misto, os pais consideram como assuntos convencionais e sob a sua jurisdição, enquanto os filhos os consideram mais do âmbito pessoal e dependentes de si próprios e da sua capacidade de decisão. Neste sentido há desacordo entre pais e filhos, isto é, quando não há coincidência na definição das áreas da autoridade, há incompreensão e o conflito.

É de salientar que para Medeiros (2000) o jogo da aceitação da diferença existe dentro da própria fratria e que é tão importante a criação de espaços individuais entre os irmãos como entre as gerações. A diferença deve ser entendida em termos etários, interesses, valores e opções individuais.

A presença dos pais junto dos filhos é tão ou mais importante nesta etapa do que na infância, em virtude de que: "o seu papel agora é de estar atentos, de mobilizar sem dirigir, de apoiar nos fracassos e incentivar nos êxitos, em suma, estar com eles e respeitar cada vez mais a sua individualização" (SAMPAIO, 1998, p. 42).

Desde alguns anos atrás, vai instalando-se em nossa sociedade, e de maneira especial em nossas escolas, a convicção de que os estudantes vão sendo cada vez mais indisciplinados e mal-ducados, mostrando comportamentos que interrompem o clima acadêmico da escola, quando não protagonizam agressões verbais e físicas, furtos, destruição do mobiliário, etc. o fato de que na escola surjam problemas de convi- vência não é nada novo. Sempre tem acontecido, se bem que o seu tratamento tem estado muito centrado nos aspectos punitivos e na seleção.

Pressupõe uma visão pobre ou psicologista das causas de problema, atribuindo-se à falta de interesse do aluno, à sua escassa capacidade, sua preguiça, ou inclusive, ao seu "caráter violento" etc., ou então se explica pela sua origem (classe social, raça, etc.), assumindo-se que os problemas sempre surgirão a partir destas classes sociais porque carecem de uma adequada educação, não tem expectativas de estudos posteriores, etc.

No entanto, estes problemas são multicausais e têm sua raiz não apenas no ambiente social e nas mudanças socioeconômicas que vão se produzindo, diante dos quais as crianças são mais vulneráveis do que os outros, quanto as suas expectativas de futuro. A educação escapou ao controle da família porque, desde pequena a criança já recebe influências da escola, dos amigos, da televisão e da internet.

A agressividade aqui colocada está focalizada como uma das manifestações da indisciplina e apresenta as seguintes razões:

a) Excesso de repressão, professor autoritário em classe, regras rígidas na escola, intolerância, etc. Podem provocar uma natural onda de revolta principalmente naqueles que não sejam passivamente submissos e queiram saudavelmente participar das atividades. Assim a indisciplina pode surgir como não aceitação do absolutismo e autoritarismo excludente. A repressão não educa;

b) Excesso de liberdade, família e professor permissivo em classe, escola sem direção, ausência de regras também na escola, etc. Quando os alunos ficam entregues aos próprios critérios de convivência, os mais abusados podem não respeitar as autoridades naturais inerente 
aos educadores, nem poupam os próprios colegas. Ausência de limites também não educa;

c) Problemas funcionais da escola, coordenador (ou diretor) desautoriza o seu próprio professor, funcionários que desacatam ou transgridem normas existentes na escola, etc. Quando os alunos percebem que podem jogar uma autoridade contra outra sejam quais forem os seus níveis hierárquico, o fazem para tirar beneficio próprio em detrimento da sua formação e capacitação, pelo prazer imediato de não ter que cumprir algo que deveria. Numa desavença entre professor e aluno ou assistente operacional e aluno, este pode desautorizá-lo já sabendo que o diretor, ou a Escola adota a filosofia do "aluno tem sempre razão";

d) "Avental comportamental" ausente no professor e no assistente operacional, à sua função pedagógica, o professor e Assistente Operacional, tem que ter consciência de ser um representante da Escola. Quando um aluno o desrespeita em classe é a Escola que está sendo atingida através do professor, e não somente ele propriamente dito. Quando cada um toma como um problema pessoal, cria na Escola um clima de anarquia, visto os professores e assistentes Operacionais serem diferentes entre si. Da anarquia nasce a indisciplina. O "avental comportamental” do professor representa o comportamento padrão dos representantes da Escola em relação às indisciplinas mais comuns. Este padrão é estabelecido no começo do ano letivo com todo o corpo docente presente que após mapear quais as indisciplinas mais comuns que ocorre na Escola votam quais os procedimentos que todos os professores devem tomar. A indisciplina do aluno deixa de ser somente um problema contra uma determinada pessoa e passa a ser entendido como um desacato à Escola; e) Pais desinteressados no aluno, mas querem aprovação, são pais retrógrados que mandam os filhos para a escola para serem aprovados e não aprenderem a ampliar o seu mundo e crescer. 0 que thes interessa é o diploma. 0 que faltar futuramente aos filhos, os pais estão dispostos a supri-los. Assim os filhos estudam o suficiente para passar de ano. Estão sendo preparados para no futuro trabalharem o suficiente para não serem despedidos quando empregados e/ou pagarem o mínimo necessário para seus empregados não os abandonarem, caso sejam empregadores;

f) Pais que terceirizam para Escola a educação dos seus filhos, hoje há pais que por perderem suas referências educativas delegam à escola a responsabilidade de educar os seus filhos. Para a escola, os alunos são meros "transeuntes curriculares" isto é, mudam de escola num piscar de olhos por qualquer motivo e saem da escola quando terminam o curso. Mais para os pais, os filhos são para sempre. Filhos são como navios.

Os pais são os estaleiros que fabricam os navios e a escola vai capacitá-los através de instrumentos que vão auxiliá-los a navegar pelos mares muitas vezes desconhecidos dos seus próprios pais. Portanto escola e pais têm funções diferentes, mas complementares.

Os pais não devem jamais abrir mão de educar seus filhos. Como ninguém consegue dar o que não tem, é importante que os pais sejam progressivos e se preparem para poder dar uma boa educação aos seus filhos. São retrógados os pais que por encontrarem dificuldades abandonam suas funções e passa a ser muito cômodo poder cobrar dos outros as suas próprias falhas, estas falhas vão gerar indisciplina;

g) Drogas, um grande problema que infelizmente 
esta aumentando, sejam elas licitas ou ilícitas, prejudicam o desempenho escolar e relacional dos alunos. 0 usuário fica à mercê dos seus defeitos químicos e sua vontade já não esta mais sob o seu controle. Assim ele passa a fazer o que a droga the permite. Uma das primeiras estruturas a serem tiradas de função é o superego. É ele que torna o indivíduo adequado a diversos meios que frequenta e que consiga ter força de vontade e produtividade.
Na ausência, o usuário fica mais a disposição dos seus instintos e vontades que não combinam com o assistir aulas, fazer provas, respeitar outras pessoas como professores, colegas, etc. É importante que os educadores estejam preparados, no mínimo informados, para lidar bem com seus usuários.

\section{CONCLUSÃO}

A imagem social da escola em Portugal encontra-se ameaçada, há uma espécie de mal-estar e uma falta aguda de credibilidade profissional, a respeito dos profissionais da área. As crianças e adolescentes ouvem discursos depreciativas a respeito da escola e dos profissionais de educação dentro de casa.

O desenvolvimento cognitivo fornece indicadores para a definição da complexidade da situação, ou seja, deve-se propor situações de aprendizagem compatíveis com o estágio atual de desenvolvimento cognitivo do aluno.
Ter-se-á que analisar, refletir e debater o que nos divide entre a escola de hoje e a escola de ontem, o que separa, mas também o que une e o que congrega, para se tentar criar, a partir da Família, da Escola e da Sociedade, as condições psicofisiológicas para perfis comportamentais que conduzam ao desenvolvimento integrado de todos, sem exceção. Para tal é preciso, sem dúvida, de ações de formação que ajude a refletir sobre esta problemática.

\section{REFERÊNCIAS}

ALMEIDA, J. Ramos de. Adolescência e maternidade. Lisboa: Fundação Calouste Gulbenkian, 1987.

ARENDS, R. I. Aprender a ensinar. Lisboa: McGraw-Hill,1997.

BRUNER, J. Para uma Teoria da Educação. Lisboa: Artes Gráficas Ltda, 1999.

CORDEIRO, M. Dos 10 aos 15 anos - Adolescentes e Adolescência. Lisboa: Quatro Margens, 1997.

CORREIA, M.; ALVES, M. Gravidez na adolescência: o nascimento de uma consulta e um programa de intervenção. Análise Psicológica, (1990) agosto, n. 4, p. 429-434. 
DAVÍDOV, V. La enseñanza escolar y el desarrollo psíquico. Espanha: Progreso, 1988.

FENWIK, E.; SMITH, T. Adolescência - Um Valioso Guia para os Pais e Adolescentes. Lisboa: Artes Gráficas,1995.

FLEMING, M. Adolescência e Autonomia - O Desenvolvimento e a Relação com os Pais. Porto: Afrontamento, 1993.

FONSECA, V. e MENDES, V. Insucesso Escolar - Abordagem Psicopedagógica das dificuldades de Aprendizagem. Lisboa: Âncora, 1977.

FOX, L. C. Peer acceptance of learning disabled children in the regular classroom - Exceptional Children. American Psychological Association. Boston,1989. 56 (1), p. 50-59.

FRASQUILHO, M. Comportamentos - Problemas em adolescentes- Factores Protectores e Educação para a Saúde. Lisboa: Laborterapia, 1996.

LEONTIEV, A. 0 desenvolvimento do psiquismo. Lisboa: Livros Horizonte, 2001.

MEDEIROS, M. T. (coord.) Adolescência: Abordagens, Investigação e Contextos de desenvolvimento. Açores: Direção Regional de Educação, 2000.

MULLER, K. Psicologia aplicada à educação. São Paulo: EPU,1977.

MUSGRAVE, P. Sociologia da Educação. Lisboa: Fundação Calouste Gulbenkian, 1979.

OLIVEIRA, M. L.; PORTO, M. M. A aprendizagem e os jovens. Lisboa: Instituto do emprego e formação profissional, 1992.

ORTH, E. L'importance de l'affectvité dans le développement mental. Les cahiers de l'enfance inadaptée, 1971, 2, p. 8-16.

OUILLON, D.; ORIGLIA, H. L’Adolescent.... Paris:Sociales françaises, 1974.

PEPIN, L. A Criança no Mundo Actual - Psicologia, vida e problemas. Lisboa: Editorial Estampa,1979.

REYMOND, R. O Desenvolvimento Social da Criança e do Adolescente. Lisboa: Editorial Aster,1995.

ROSARIO, O. e ROSARIO, R. Estratégias educativas para a prevenção da violência. Brasília: UNESCO, UCB, 2002.

SAMPAIO, D. A cinza do tempo. Lisboa: Caminho,1997.

SAMPAIO, D. Vivemos livres numa prisão. Lisboa: Caminho, 1998. 
SILVA, A. Desenvolvimento de competências sociais nos adolescentes. Lisboa: edições Climepsi, 2004.

SILVA, A. Desenvolvimento infantil. Lisboa: edições Climepsi, 2011.

SYLVA, K., LUNT, I. Iniciação ao desenvolvimento da criança. São Paulo: Martins Fontes, 1994

SPRINTHALL, N. A .; COLLINS, W. A. Psicologia do adolescente. Lisboa: Fundação Calouste Gulbenkian, 1999.

SPRINTHALL, N. A.; SPRINTHALL, R. C. Psicologia educacional. Lisboa: Mcgraw-Hill, 1994.

VYGOTSKY, L.S. Obras escogidas. v. III. Madrid: Visor, 1995. 